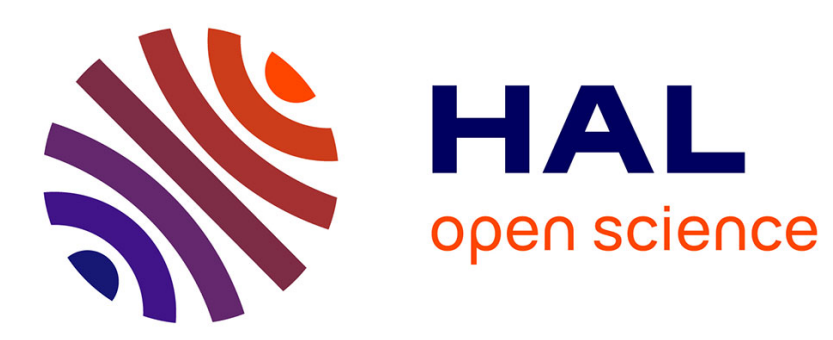

\title{
Properties of rubidium-argon Van der Waals molecules from the relaxation of polarized $\mathrm{Rb}$ atoms
}

\author{
M.A. Bouchiat, J. Brossel, P. Mora, L. Pottier
}

\section{To cite this version:}

M.A. Bouchiat, J. Brossel, P. Mora, L. Pottier. Properties of rubidium-argon Van der Waals molecules from the relaxation of polarized Rb atoms. Journal de Physique, 1975, 36 (11), pp.1075-1077. 10.1051/jphys:0197500360110107500 . jpa-00208351

\section{HAL Id: jpa-00208351 https://hal.science/jpa-00208351}

Submitted on 1 Jan 1975

HAL is a multi-disciplinary open access archive for the deposit and dissemination of scientific research documents, whether they are published or not. The documents may come from teaching and research institutions in France or abroad, or from public or private research centers.
L'archive ouverte pluridisciplinaire HAL, est destinée au dépôt et à la diffusion de documents scientifiques de niveau recherche, publiés ou non, émanant des établissements d'enseignement et de recherche français ou étrangers, des laboratoires publics ou privés. 


\title{
PROPERTIES OF RUBIDIUM-ARGON VAN DER WAALS MOLECULES FROM THE RELAXATION OF POLARIZED Rb ATOMS
}

\author{
M. A. BOUCHIAT, J. BROSSEL, P. MORA, L. POTTIER \\ Laboratoire de Spectroscopie Hertzienne $(*)$, Ecole Normale Supérieure \\ 75231 Paris Cedex 05, France
}

(Reçu le 16 mai 1975, accepté le 23 juin 1975)

\begin{abstract}
Résumé. - Nous avons mesuré entre 0,1 et $10 \mathrm{G}$ la relaxation d'atomes de rubidium polarisés optiquement, en présence d'argon entre 0,1 et 5 torrs. La relaxation est due principalement au couplage spin-rotation dans les molécules de Van der Waals RbA. L'interprétation des données expérimentales fournit des paramètres moléculaires tels que la valeur moyenne du couplage spinrotation $(\bar{\gamma} / h=0,105 \mathrm{MHz})$, la durée de vie moléculaire $\left(\tau=4,85 \times 10^{-8} \mathrm{~s}\right.$ à 1 torr $)$ et la constante d'action de masse de l'équilibre chimique $\mathrm{Rb}+\mathrm{A} \rightleftharpoons \mathrm{RbA}\left(\kappa=94 \AA^{3} /\right.$ molécule à $\left.300 \mathrm{~K}\right)$.
\end{abstract}

\begin{abstract}
Relaxation rate measurements have been performed between 0.1 and $10 \mathrm{G}$ on optically polarized $\mathrm{Rb}$ atoms in Argon at pressures ranging from 0.1 to 5 torrs. The relaxation is mainly induced by spin-rotation coupling in RbA Van der Waals molecules. Interpretation of the data gives molecular parameters such as the average spin-rotation constant $(\bar{\gamma} / h=0.105 \mathrm{MHz})$, the molecular lifetime $\left(\tau=4.85 \times 10^{-8} \mathrm{~s}\right.$ at 1 torr) and the constant of mass action for the chemical equilibrium $\mathrm{Rb}+\mathrm{A} \rightleftharpoons \mathrm{RbA}\left(\kappa=94 \AA^{3} /\right.$ molecule at $\left.300 \mathrm{~K}\right)$.
\end{abstract}

We have measured the relaxation rate of the ground state electronic polarization of optically polarized rubidium atoms in argon at pressures ranging from 0.1 to 5 torrs in an externally applied d.c. magnetic field of 0.1 to 10 gauss. It is now well known that this is a mean of investigating alkali-rare-gas interactions that is especially sensitive to elementary processes of long duration : it has been possible to detect the formation and destruction of Rb-rare-gas molecules at low pressures when they constitute a very tiny proportion of the alkali-rare-gas mixture, for example when their partial pressure is only $10^{-13}$ torr ; the reason is simply that molecular formation lengthens considerably the duration of the disorienting interaction and thus enhances its effect $[1,2]$. These molecules are loosely bound by the long range dispersion forces; the binding energy for RbA is only a few $10^{-3} \mathrm{eV}$. The electronic spin relaxation takes place under the action of the spin-rotation interaction inside molecules that are formed in three-body collisions and dissociated at the next molecule-atom collision. The strength of the disorienting process is so small, roughly $10^{-8} \mathrm{eV}$, that it can be most easily masked by the effect of other relaxation mechanisms. Previous measurements were performed for $\mathrm{RbKr}$ because they

$\left(^{*}\right)$ Laboratoire associé au Centre National de la Recherche Scientifique. could be extended over a wide pressure range, so that experimental data were rich enough to allow a detailed description of the disorienting mechanism $[2,3]$. The studies reported up to now on other alkali-rare-gas pairs $[3,4]$ were not carried out in such detail. The experimental results which we obtained a few years ago for $\mathrm{RbA}$ [3] were incomplete; the difficulty encountered in this case was caused by the smallness of the relaxation rates induced by molecule formation : they are smaller for $\mathrm{RbA}$ than for $\mathrm{RbKr}$ by two orders of magnitude and they compare in magnitude with the relaxation rates induced by wall collisions, even in deuterated-paraffin coated cells [5]. In order to be able to extract values for the parameters of the RbA molecule from these incomplete experimental data, we replaced the lacking experimental information by theoretical estimates, computed from a guessed interatomic potential since the true one was not known [3] (see below eq. (1)). A new experimental study had therefore to be performed with increased sensitivity and extended care for the preparation of the samples; the purpose of the present paper is to report the results of this new study. It appears that they are in remarkably good agreement with the previous half-guessed ones.

The experimental set-up, already used and described in a previous work [3], is given in figure 1 . It consists of a pumping light beam which produces the orientation, 


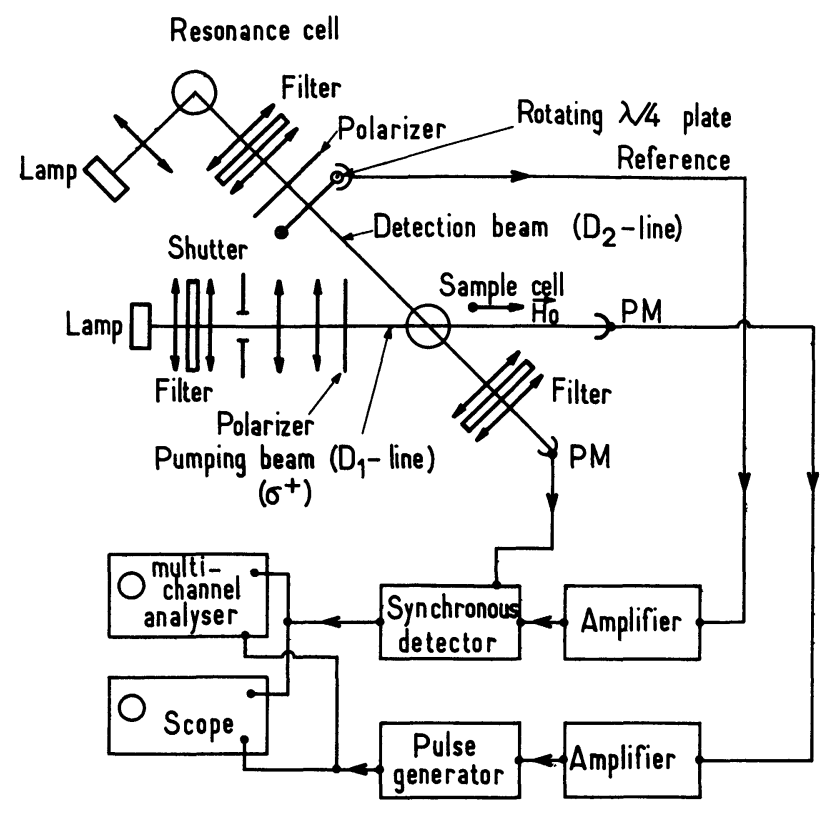

FIG. 1. - Schematic diagram of the experimental apparatus.

and a detecting light beam of low intensity, monitoring the $\mathbf{R b}$ polarization. Substantial improvement was obtained by modulating its polarization with a rotating air-suspended quarterwave plate placed between a fixed polarizer and the $\mathrm{Rb}$ cell. The modulated photocurrent, proportional to the difference between the amounts of light absorbed on the detecting beam in states of right and left circular polarization, is detected in a phase sensitive lock-in amplifier. When the optical pumping is suddenly turned off, the output of the lock-in amplifier undergoes a transient decay which is recorded on a scope and in a multichannel analyzer triggered by the optical shutter. (The modulation period $\left(1.12 \times 10^{-2} \mathrm{~s}\right)$ is short compared to the relaxation time.) At least two sets of 60 transients were averaged to obtain each relaxation time measurement. Figures $2 a$ and $2 b$ show the relaxation rate versus the d.c. magnetic field for the pure isotope ${ }^{87} \mathrm{Rb}$ at two different argon pressures. The Lorentz-like field dependence, of amplitude $A$ and half-width $\Delta H_{0}$, is interpreted as induced by sticking collisions, i.e. collisions with formation of a molecule, and the high-field limit rate corresponds to all other processes, i.e. wall collisions and usual sudden gas collisions (binary). Figure 3 represents the pressure dependence $A(P)$ of the amplitude, now extended well out of the pressure range where sticking collisions are weak $(A(P)$ pressure independent), into the low-pressure range where sticking collisions become strong. The characteristic half-width $\Delta H_{0}$ is plotted as a function of the pressure in figure $4:$ we note at low pressures a departure from the linear variation previously observed which was typical of sticking collisions being weak. For a more detailed interpretation the reader is referred to references [2] and [3]. All experimental data have been fitted with theoretical curves (see Fig. 10, 11 and 12 of reference [2]) which depend on three

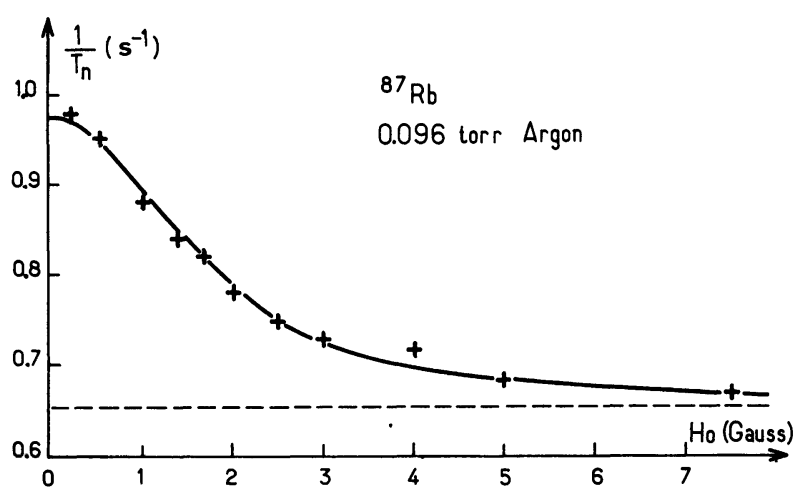

a)

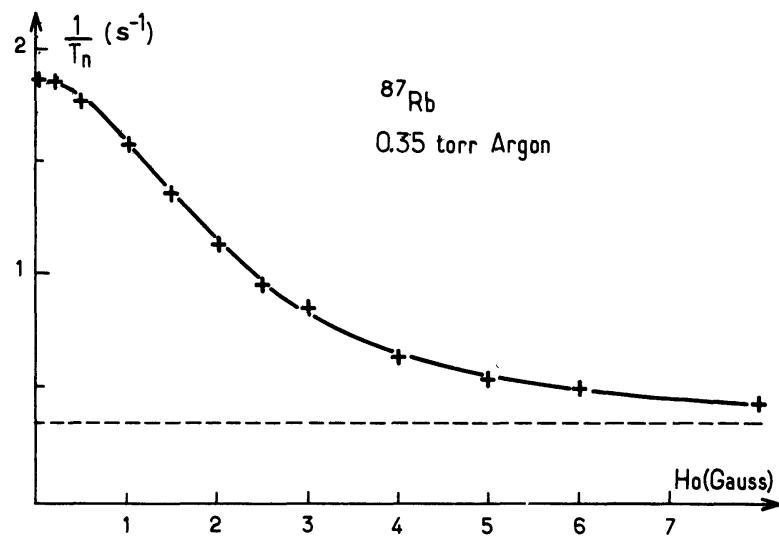

b)

Fig. 2. - The relaxation rate $T_{n}^{-1}$ of ${ }^{87} \mathrm{Rb}$ versus the d.c. field in argon at two pressures $a$ ) 0.096 torr, $b$ ) 0.35 torr.

Crosses : experimental points. Solid curve : theoretical curve the deviation from a pure Lorentz curve at low pressures is taken into account).

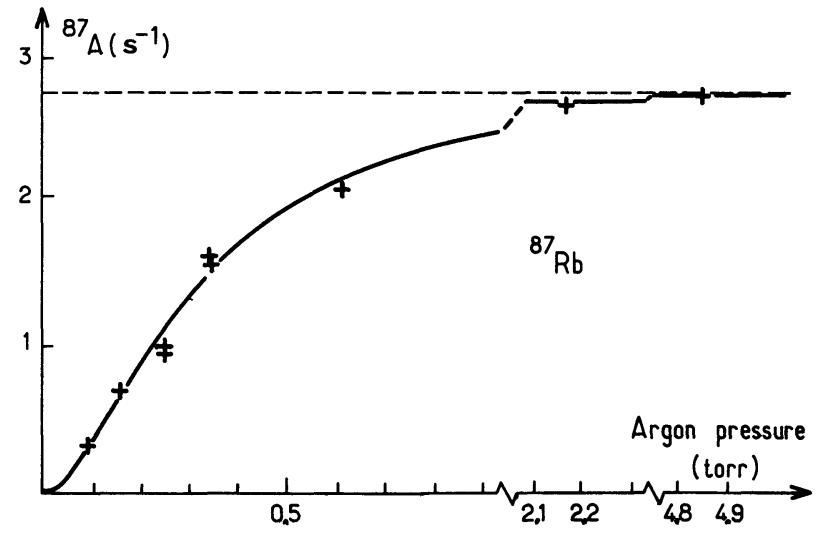

FIG. 3. - Pressure dependence of the amplitude $A$ for ${ }^{87} \mathrm{Rb}$ in argon. Experimental points and theoretical curve.

parameters $H_{1}^{*}, P^{*}, A^{*}$ that have simple physical interpretations : $H_{1}^{*}$ is the root mean square value of the effective magnetic field simulating the spin-rotation interaction $\gamma \mathbf{S} . \mathbf{N} ; P^{*}$ is the pressure at which the average lifetime $\tau$ is equal to $(2 \pi)^{-1}$ times the Larmor period of the atomic angular momentum $\mathbf{F}$ in the field $H_{1}^{*} ; A^{*}$ is the asymptotic value of $A$ at high pressures where the motion-narrowing condition 


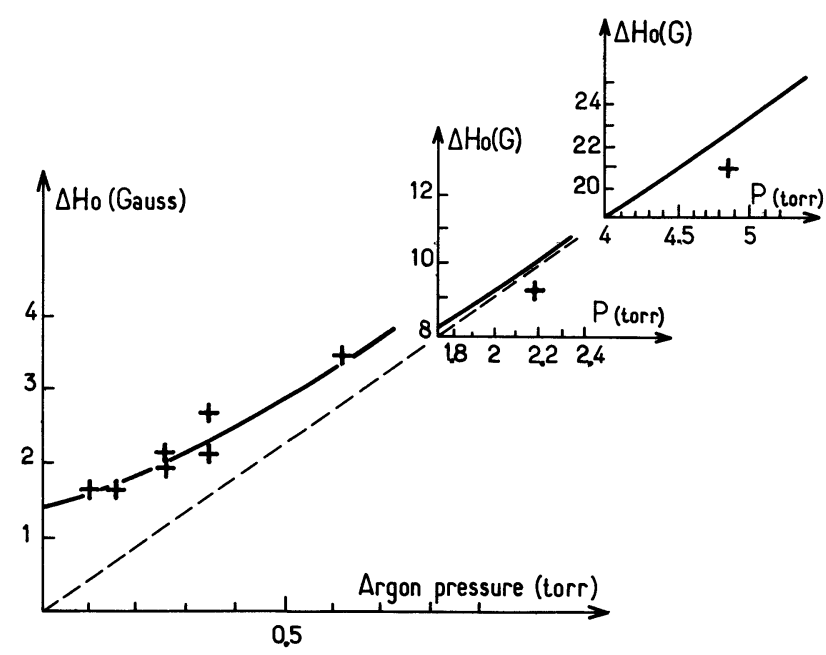

FIG. 4. - Pressure variation of the half-width $\Delta H_{0}$ for ${ }^{87} \mathrm{Rb}$ in argon. Experimental points and theoretical curve.

$\omega_{1}^{2} \tau^{2} \ll 1$ is fulfilled. We can thus proceed to the determination of the parameters giving the best agreement between theory and experiment. The results of this three-parameter fit are illustrated by the solid curves of figures 3 and 4, in good agreement with the experimental points. The corresponding values of the parameters $H_{1}^{*},{ }^{87} P^{*},{ }^{87} A^{*}$ are :

$$
\begin{aligned}
H_{1}^{*} & =1.19 \pm 0.05 \text { gauss } \\
{ }^{87} P^{*} & =0.254 \pm 0.015 \text { torr } ; \\
{ }^{87} A^{*} & =2.68 \pm 0.16 \mathrm{~s}^{-1} .
\end{aligned}
$$

(The uncertainties quoted here are the r.m.s. uncertainties estimated from the experimental data; in view of the small number of experimental points, it is reasonable to assume that the true values may differ from the measured ones by as much as \pm 3.5 times the r.m.s. uncertainties $\left({ }^{1}\right)$.) From these values we can deduce the constant of mass action of the chemical equilibrium $\mathrm{Rb}+\mathrm{A} \rightleftharpoons \mathrm{RbA}$ :

$$
\kappa=94 \pm 6 \AA^{3} / \text { molecule (for } T=300 \mathrm{~K} \text { ). }
$$

This number corresponds to a proportion of one bound $\mathrm{Rb}$ atom in $3.3 \times 10^{5}$ free $\mathrm{Rb}$ atoms at an argon pressure of 1 torr. One can also obtain the destruction and formation rates for $P=1$ torr :

$\tau^{-1}=(2.06 \pm 0.08) \times 10^{7} \mathrm{~s}^{-1} ; T_{\mathrm{f}}^{-1}=62 \pm 5 \mathrm{~s}^{-1}$

( $\left.{ }^{1}\right)$ Within the quoted experimental accuracy, it appears that the experimental values given here agree with the ones previously [3] measured $\left({ }^{87} A^{*}\right)$ or obtained by combined use of experimental results and of the guessed interatomic potential $\left(H_{1}^{*},{ }^{87} P^{*}\right)$. leading to an average breaking cross-section

$$
\bar{\sigma}=139 \pm 6 \AA^{2} \text {. }
$$

If the $\mathrm{Rb}-\mathrm{A}$ interatomic potential were known, some of these parameters could be computed, particularly the constant of mass action $\kappa$ given theoretically by :

$$
\kappa=\lambda_{T}^{3} \sum_{v, N}(2 N+1) \mathrm{e}^{-E(v, N) / k T} .
$$

In this relation the sum extends over all molecular rotational-vibrational states $(v, N)$ of energy $E(v, N)$, and $\lambda_{T}$ is given in terms of the reduced mass $\mu$ by $\lambda_{T}=\hbar(2 \pi / \mu k T)^{1 / 2}$. Unfortunately we have not found accurate potential data for the Rb-A pair in the literature. Using theoretical results [6] and experimental data relative to other alkali-rare gas pairs [7], we concluded that a reasonable representation of this potential should be given by a (12-6) Lennard-Jones potential of energy depth $\varepsilon$ and radius at minimum $r_{\mathrm{m}}$ such that :

$$
\left.\begin{array}{l}
0.54<\varepsilon<0.57 \quad 10^{-2} \mathrm{eV} \\
5.0<r_{\mathrm{m}}<5.3 \AA
\end{array}\right\} .
$$

We thus deduced the theoretical value of $\kappa$ :

$$
72<\kappa_{\text {th }}<93 \AA^{3} / \text { molecule },
$$

which is in good agreement with the experimental value. With the same potential we computed the r.m.s. value of the rotational quantum number at thermal equilibrium

$$
30.5<N^{*}<33.3,
$$

which can be used to deduce from the r.m.s. molecular field $H_{1}^{*}$ the average value $\bar{\gamma}$ of the spin-rotation coupling constant taken over all rotation-vibrational states :

$$
0.087<\bar{\gamma} / h=\frac{\gamma_{\mathrm{S}} H_{1}^{*}}{h N^{*}}<0.123 \mathrm{MHz}
$$

We finally conclude that for rubidium in argon as well as in krypton the simple model used to describe the relaxation induced by spin-rotation coupling during the molecular lifetime is tested and found to be valid in a wide pressure range corresponding to quite different disorientation probabilities per single $\mathrm{Rb}$-gas interaction. Reliable values of the molecular parameters are thus deduced from the relaxation rate measurements.

\section{References}

[1] Aymar, M., Bouchiat, M. A., Brossel, J., Phys. Lett. 24A (1967) 753.

Bouchiat, M. A., Brossel, J. and Pottier, L., Phys. Rev. Lett. 19 (1967) 817.

[2] Bouchiat, C., Bouchiat, M. A., Pottier, L., Phys. Rev. 181 (1969) 144.

[3] Bouchiat, M. A., Brossel, J. and Pottier, L., J. Chem. Phys. 56 (1972) 3703.

[4] Beverini, N., Violino, P. and Strumia, F., Z. Phys. 265 (1973) 189.

BeVerinI, N., Thesis, Pisa (Italy), 1973 (unpublished).
[5] Bouchiat, M. A., Brossel, J., Phys. Rev. 147 (1966) 41.

[6] Baylis, W. E., J. Chem. Phys. 51 (1969) 2665.

[7] Bernstein, R. B. and Muckerman, J. T., Advances in Chemical Physics (edited by J. O. Hirschfelder, Interscience, N. Y.), 1967, vol. 12, p. 389.

Von Busch, F., Strunck, H. J. and Schlier, Ch., Z. Phys. 199 (1967) 518.

Buck, U. and Pauly, H., Z. Phys. 208 (1968) 390.

Nikiforov, E. V. and ShCherba, L. S., Sov. Phys. Optics and Spectroscopy 32 (1972) 567. 